\title{
Oral tolerance: \\ Recent advances on mechanisms and potential applications
}

\author{
Thaniya Sricharunrat, ${ }^{1}$ Pornpan Pumirat, ${ }^{2}$ Pornsawan Leaungwutiwong ${ }^{2 *}$
}

\begin{abstract}
Oral tolerance is a type of immune hypo-responsiveness induced by oral administration of food or harmless gastrointestinal antigens. It is evident that the induction of oral tolerance can protect our body from enteric problems, such as food allergies and colitis caused by autoimmunity. Here we review the immunological mechanisms of oral tolerance, the role of $\mathrm{T}$ cell cytokines in generating tolerance and the impact of Peyer's patches and mesenteric lymph nodes, and discuss the part played by commensal microflora in the regulation and maintenance of the intestinal barrier. The potential clinical applications of oral tolerance in human disease therapy are also included in this review. Understanding the mechanisms of oral tolerance may lead to the development of alternative strategies for preventing or suppressing the symptoms of autoimmune diseases and allergies.
\end{abstract}

Key words: Oral tolerance; immune system; mucosal tissues; microflora; clinical trial

\author{
From: \\ Pathology Unit, Chulabhorn Hospital, Chulabhorn Royal Academy, \\ Bangkok, Thailand \\ 2 Department of Microbiology and Immunology, \\ Faculty of Tropical Medicine, Mahidol University, Bangkok, Thailand
}

\author{
* Corresponding author: \\ Pornsawan Leaungwutiwong \\ Department of Microbiology and Immunology, Faculty of Tropical \\ Medicine, Mahidol University, Bangkok, Thailand \\ 420/6 Ratchawithi Road, Ratchathewi, Bangkok, 10400, Thailand \\ E-mail: pornsawan.lea@mahidol.ac.th
}

\section{Introduction}

The immune response functions to prevent invasion of pathogens and also includes suppression tolerance mechanisms to prevent targeting self-antigens and the development of autoimmunity. Tolerance can occur both in developing and mature lymphocytes (central and peripheral immune tolerance, respectively).

In central immune tolerance, immature or developing $\mathrm{T}$ and $\mathrm{B}$ cells that react strongly to self-antigens are eliminated by clonal deletion. ${ }^{1}$ However, clonal deletion is not perfect because some self-reactive $\mathrm{T}$ cells may not react strongly enough to induce deletion signals and antigens must be present in the thymus to induce central tolerance. Peripheral tolerance occurs outside of primary lymphoid organs (the thymus and bone marrow). Mechanisms of peripheral tolerance include clonal anergy (lymphocytes fail to respond), deletion of chronically activated T cells (activation induced cell death) and suppression by regulatory immune cells. ${ }^{2,3}$

The most common methods to induce tolerance to non -harmful antigens in humans and animals involve introducing proteins or peptides without adjuvants by intravenous injection, portal vein injection, intranasal administration, oral mucosal or sublingual administration or gastrointestinal mucosal administration or skin administration. ${ }^{4,5}$ However, oral tolerance remains the most rigorously investigated form of tolerance because the oral administration of proteins or peptides can lead to the induction of systemic and local unresponsiveness to innocuous antigens. A benefit of induced mucosal tolerance (orally or nasally) is that it is non-invasive. However, when inducing mucosal tolerance with normal food antigens or synthetic antigens a high amount of antigen is needed, as compared with systemic (intradermal) induction and an adjuvant may be needed in some situations.

The capability to induce oral tolerance has been recognized for decades. Many studies of induced oral tolerance have been performed using animal models and several have been performed using human subjects. ${ }^{6}$ The aims of most oral tolerance studies have been to prevent and treat diseases, particularly allergic and autoimmune diseases (ADs), and even to prevent transplantation rejection. ${ }^{7}$ The aim of this review was to focus on the key issues of oral tolerance, particularly the mechanisms of induced oral tolerance, the roles of the immune system, mucosal tissues and commensal microflora and the application of oral tolerance in humans. Furthermore, a comprehensive conclusion on oral tolerance with an emphasis on future research directions is provided. 


\section{Mechanisms of oral tolerance induction}

Many experiments aimed to explain the mechanism of oral tolerance induction have been performed using animals with varying doses of antigens, mostly ovalbumin, in the feed. Oral tolerance occurs after either administration of a single high dose of antigen (>20 mg) or repeated exposure to lower doses $(100 \mathrm{ng}-1 \mathrm{mg}){ }^{8}$ These two forms of tolerance, now termed high- and low-dose tolerance, are mediated by distinct mechanisms. The proposed mechanisms of oral tolerance involve clonal anergy, deletion (apoptosis) of antigen-specific $\mathrm{T}$ cells, active immune suppression, bystander suppression, and antibody response (Figure 1). Both CD4+ T helper (Th) and CD8+ cytotoxic $\mathrm{T}$ cells are important for oral tolerance induction. A subset of Th cells, including Th1, Th2 and regulatory T cells (Tregs), is most often associated with oral tolerance. However, the exact mechanisms of oral tolerance induction by Th9, Th17 and Th22 cells remain unknown. ${ }^{9}$

Feeding of mice with a high dose of antigen results in anergy of antigen-specific T cells in the Peyer's patches (PPs), mesenteric lymph nodes (MLNs), spleen and peripheral lymph nodes (LNs). This strategy also induces apoptosis of antigen -specific $\mathrm{T}$ cells in PPs. However, transferring $\mathrm{T}$ cells from mice fed a high dose of antigen to naïve mice failed to transfer tolerance. $^{2}$

In contrast, feeding a lower dose of antigen induced proliferation of antigen-specific $\mathrm{T}$ cells and subsequent secretion of cytokines, particularly interleukin (IL)-4, IL-10 and transforming growth factor-beta (TGF- $\beta$ ), resulting in suppression of the Th1 immune response. ${ }^{10} \mathrm{CD} 4+$ and CD8+ $\mathrm{T}$ cells isolated from mice fed a low antigen dose were able to transfer immunity against further immunization with the same antigen when administered to naïve mice. ${ }^{11}$ In contrast, feeding either a high or low dose of ovalbumin antigen to rats with ovalbumin-induced arthritis resulted in $\mathrm{T}$ cell anergy that could not be transferred to naïve rats. ${ }^{12}$

In IL-4-deficient mice, feeding a high dose of ovalbumin suppressed both Th1 and Th2 responses, and induced tolerance. Likewise, tolerance was induced in both Th1- and Th2-defective mice by feeding a high dose of ovalbumin. These results indicate that oral tolerance can be induced independently of Th1 or Th2 cytokines. $^{13}$ Moreover, feeding mice a high or low Ag dose was associated with increased TGF- $\beta$ production by stimulated splenocytes. Furthermore, feeding mice a high Ag dose reportedly induced proliferation of a specific $\mathrm{T}$ - cell subset with an activated phenotype (increased CD69 and CTLA-4 with decreased CD45RB and CD62L expression) and secretion of the cytokines interferon (IFN)- $\gamma$, IL- 4 and IL-10 in the PPs or MLNs soon after feeding and prior to anergy or apoptosis. ${ }^{2}$

Oral antigen administration can induce systemic immune tolerance via bystander suppression, which occurs when tolerance is developed against one antigen, such as by oral administration, and then that antigen is administered in combination with a second antigen, resulting in tolerance to both. Bystander suppression can be induced by a specific antigen and then suppressed in an antigen-nonspecific manner.

The mechanism of bystander suppression may best be explained by the microenvironment at the priming site where a tolerized antigen might induce hyporesponsiveness to a second antigen. Bystander suppression does not reflect clonal deletion or reduced clonal expansion of $\mathrm{T}$ cells specific to the bystander antigen. ${ }^{14}$ Upon serum transfer, CD25+ Tregs play a role in the suppression of $\mathrm{T}$ cell proliferation. ${ }^{15}$ Bystander suppression may be used to induce tolerance when the immunogenic antigen is unknown. Repeated low-dose ingestion of an antigen leads to induction of antigen-specific Tregs that have suppressor activity. Various Treg populations may be induced, including TGF- $\beta$-producing CD4+ Th cells and gut-derived antigen-specific CD4+/CD25+/Foxp3+ T cells, also known as induced Tregs (iTregs). ${ }^{16,17}$ While various T-cell subsets with regulatory activity have been shown to confer tolerance in transfer experiments, gut-derived iTregs are critical for oral tolerance induction as deletion of iTregs in a DEREG (DEpletion of REGulatory $\mathrm{T}$ cells) mouse model resulted in loss of tolerance. ${ }^{18}$ In contrast, naturally occurring thymus-derived Tregs do not appear to be required for successful oral tolerance induction. ${ }^{19}$

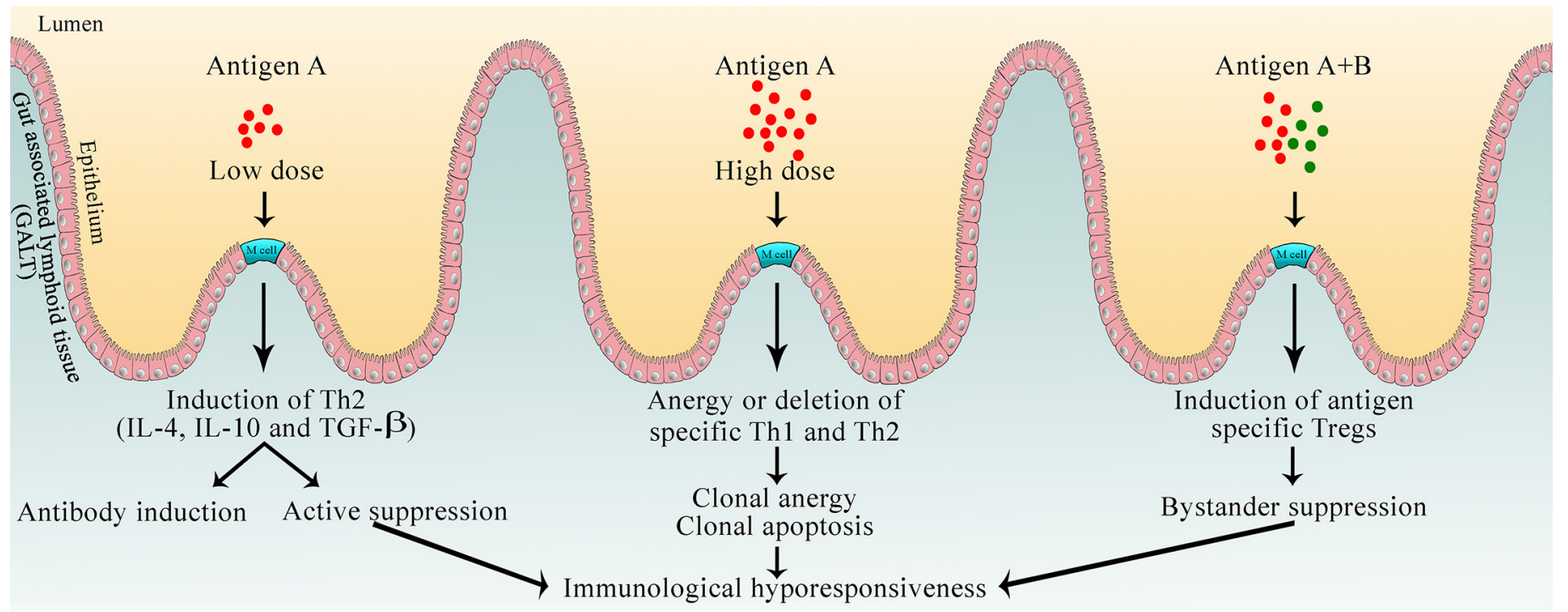

Figure 1. Mechanisms of immunological hyporesponsiveness include active immune suppression, clonal anergy, cell deletion (apoptosis), bystander suppression and antibody induction. 
In human adults, the oral antigen uptake which can persuade systemic immune response are poorly understood. The tolerance to food antigens (bovine gamma globulin, ovalbumin and soybean) is dose specific and usually mediated by $\mathrm{T}$ cell anergy. A study of repeated low dose and single high dose of keyhole limpet hemocyanin (KLH) has been documented in healthy volunteers. Repeated low dose oral KLH induced antigen specific CD4+ $\mathrm{T}$ cells for the gut homing receptor integrin b7 and the cytokines IL-2 and TNF- $\alpha$. Oral feeding of KLH increased a subsequent parenterally induced systemic CD4+ T-cell response and cytokine production of IL-4 and IL-10, whereas IFN-c, IL-2 and TNF- $\alpha$-producing cells were decrease. In contrast, a single high dose oral KLH had less effect on antigen-specific immune responses comparing with repeated low dose oral KLH. ${ }^{20}$ Foxp3+ Tregs play a key role in controlling the magnitude of immune responses to the antigens. One study reported that a low dose antigen promotes induction of Foxp3+ in human CD4+ cells. ${ }^{21}$ Besides, these Tregs not only suppress Ag-specific responses, but also mediate bystander suppression. Bystander suppression of T cells specific to the tetanus toxoid was detected after tolerance induced by bovine gamma globulin or ovalbumin with heterogeneity in the responses between individuals and types of food antigens. ${ }^{22}$

Table 1 summarizes the studies of high and low dose tolerance in this context. Overall, these studies of antigenic exposure in both mice and human suggest that the different mechanisms of oral tolerance are determined by the dose of fed antigen. These mechanisms are mutually inclusive manner, which more than one mechanism may be functional with the same antigen.

Table 1. Dose tolerance studies performed in Animals and human

\begin{tabular}{|c|c|}
\hline \multicolumn{2}{|c|}{ Animal Studies } \\
\hline High Dose Tolerance & Low Dose Tolerance \\
\hline $\begin{array}{l}\text { 1. Anergy of antigen-specific T } \\
\text { cells in PPs, MLNs, spleen and } \\
\text { peripheral LNs. } \\
\text { 2. Apoptosis of antigen-specific T } \\
\text { cells in PPs. } \\
\text { 3. Suppression of Th1 and Th2 } \\
\text { responses in IL-4-deficient } \\
\text { mice. }{ }^{13} \\
\text { 4. Induced proliferation of a } \\
\text { specific T- cell subset with } \\
\text { an activated phenotype and } \\
\text { secretion of the cytokines such } \\
\text { as IFN- } \gamma, \text { IL-4 and IL-10 in the } \\
\text { PPs or MLNs. }{ }^{2}\end{array}$ & $\begin{array}{l}\text { 1. Induced proliferation of } \\
\text { antigen-specific T cells and } \\
\text { subsequent secretion of } \\
\text { cytokines, particularly IL-4, } \\
\text { IL-10 and TGF- } \beta \text {. }^{10} \\
\text { 2. Immunity transferred via CD4+ } \\
\text { and CD8+ T cells from } \\
\text { immunized mice to naïve } \\
\text { mice. }^{11} \\
\text { 3. } \text { Induction of iTregs. }^{16,17}\end{array}$ \\
\hline \multicolumn{2}{|c|}{ Human Studies } \\
\hline High Dose Tolerance & Low Dose Tolerance \\
\hline $\begin{array}{l}\text { Induction of CD4+ T cell } \\
\text { periferation without } \\
\text { antigen-specific response. }{ }^{20}\end{array}$ & $\begin{array}{l}\text { 1. Induction of antigen-specific } \\
\text { CD4+ T cells, antigen-specific } \\
\text { IgG1, IgG3 and IgG4, IL-2, IL-4 } \\
\text { and TNF- } \alpha^{20} \\
\text { 2. Induction of Tregs by } \\
\text { suppressing Ag-specific } \\
\text { responses, together with } \\
\text { bystander suppression. }{ }^{21}\end{array}$ \\
\hline
\end{tabular}

Another mechanism of oral tolerance is through induction of antibodies. Tolerance to antigens can be transferred using serum from antigen-fed mice. ${ }^{23,24}$ Administration of IgG antibodies to mice can also suppress IgE-mediated hypersensitivity by mast cells. ${ }^{25}$ In human, early introduction of peanut in children resulted in increased peanut-specific IgG4 that conferring protection against peanut allergy. ${ }^{26}$ Perezabad et al. reported that the oral food desensitization in children involves decreased reactivity of mast cells and basophils, increased food-specific IgG4 antibodies, and eventually decreased food-specific IgE antibodies. ${ }^{27}$ Thus, the role of antibodies appear to be crucial for oral tolerance induction, but the mechanisms underlying this effect remains to be determined.

\section{Role of cytokines in oral tolerance}

Although no single mechanism is solely responsible for tolerance, cytokines play important roles in oral tolerance induction. Over the past several years, much attention has focused on the function of various $\mathrm{T}$ cell-secreted cytokines in tolerance induction.

$\mathrm{T}$ cell-produced cytokines are classified into six groups: Th1 cytokines, such as IL-2 IL-12 and IFN- $\gamma$, which stimulate cell-mediated immune responses, Th2 cytokines, such as IL-4, IL-5, IL-10 and IL-13, which stimulate antibody production during an allergic reaction that counteract Th1 cytokines, Th17 cytokines, such as IL-17 and IL-17F, which are involved in the host defense against extracellular pathogens, Th22 cytokines, such as IL-22, which induces human skin-homing memory $\mathrm{T}$ cells and functions in host defense at mucosal surface as well as in tissue repair, Th9 cytokines, such as IL-9, which are associated with the immunopathology of asthma, and regulatory T (Treg) cytokines, such as IL- 10 and TGF- $\beta$, which suppress $\mathrm{T}$ cell proliferation and regulate the functions of macrophages, as well as Th1 and Th2 effector T cells. A dominance of Th1 cytokines plays a negative role in oral tolerance and causes a loss of tolerance, whereas a dominance of Th2 and Treg cytokines plays a positive role and promotes oral tolerance by suppressing the Th1 response (Table 2)..$^{29,33,35,36,38-40,72,73}$ Food and non-harmful antigens normally induce the Th2 or regulatory cytokine response. ${ }^{28}$ For example; TGF- $\beta$-producing cells are increased in the colonic tissue of mice in response to oral tolerance to haptenized colonic proteins, and in the brain of mice with tolerance to myelin basic protein (MBP). The PPs of mice fed three times with low doses of interphotoreceptor retinoid-binding protein and systemically administered IL-2 had secreted more TGF- $\beta$, IL- 4 and IL-10 after antigen stimulation. In addition, the splenocytes of mice fed with a low dose of MBP secreted higher levels of IL-4, IL-10 and TGF- $\beta$ after stimulation.

\section{Table 2. Role of cytokine in oral tolerance}

\begin{tabular}{|l|l|}
\hline \multicolumn{1}{|c|}{ Cytokines with positive roles } & Cytokines with negative roles \\
\hline 1. Th2 cytokines: IL- $4,{ }^{29,32,33,36}$ & Th1 cytokines: IL-12, ${ }^{35}$ IFN- $\gamma^{38-40}$ \\
IL-13 $3^{9,32,33}$ & \\
2. Treg cytokines: IL-10, ${ }^{29,32,36}$ & \\
TGF- $\beta^{29,31,35}$ & \\
3. Others: macrophage-derived & \\
IL- $1 \beta^{72}$ ILC3-derived \\
GM-CSF, ${ }^{72}$ ILC3-derived IL-22
\end{tabular}


Furthermore, the peripheral LNs from mice fed hen egg white lysozyme had higher IL- 4 and TGF- $\beta$ production after antigen stimulation. Another study demonstrated that oral administration of staphylococcal enterotoxin A enhanced the immune tolerance to MBP in the gut mucosa by increasing IL-10 and TGF- $\beta$ levels. ${ }^{29}$ Recently, TGF- $\beta$ present in the milk also enhanced the generation of tolerance to antigens carried in the breastmilk. ${ }^{30}$

T-cell proliferation was decreased in TGF- $\beta$ knockout mice fed a high dose of antigen. However, feeding TGF- $\beta$ knockout mice a low dose of antigen also resulted in decreased $\mathrm{T}$ cell proliferation, but to a lesser degree than in normal mice. TGF- $\beta$ knockout mice and normal mice fed a low dose of antigen have decreased cytokine production (IL-10, IL-4 and IFN- $\gamma$ ), suggesting that TGF- $\beta$ might not be the exclusive mechanism for tolerance, particularly in this mouse model for which tolerance was induced by feeding a low antigen dose rather than inhibition of cytokine production. Thus, tolerance might be induced by clonal anergy. ${ }^{11}$ These findings indicate that cytokines play important roles in the regulation of mucosal immune responses. Other studies have indicated that TGF- $\beta$ can convert peripheral CD25-/CD4+ T cells to CD25+/CD4+ $\mathrm{T}$ cells that have a phenotype and function resembling those of natural Tregs, which may be caused by TGF- $\beta$-induced expression of Foxp 3 and CTLA-4, and induction of anergy of CD25-/CD4+ T cells in a contact-dependent manner, leading to reduced secretion of cytokines by Th1 and Th2 cells. In this study, IL-10 had no role in the conversion of CD25- T cells to CD25+ T cells. ${ }^{31}$

Numerous studies have demonstrated that the administration of specific cytokines can induce oral tolerance. For example, feeding IL-10 or IL- 4 together with an oral antigen enhanced the development of oral tolerance compared with feeding of the antigen alone. The administration of IL-4 intraperitoneally together with $\mathrm{MBP}$ feeding also reduced the severity of experimental autoimmune encephalomyelitis (EAE), while injection of IL-4 or feeding MBP alone did not. This study also found that IL- 4 can induce TGF- $\beta$ secretion by T cells in vitro, while culture with IL- 4 and IL-13 induced the generation of peripheral CD25+ Tregs with an anergic phenotype that suppressed the proliferation of CD25-T cells in vitro. ${ }^{32}$ IL-4 and IL-13 can downregulate expression of tolllike receptors (TLR)- 3 and -4 , and secretion of IL- 8 in human intestinal epithelial cell lines, suggesting that signalling of IL- 4 and -13 is decreased through TLR-3 and $-4 .{ }^{33}$ Also, TLR2 activators were recently found to modulate oral tolerance in mice $^{34}$ however; the role of TLR2-mediated cytokines in oral tolerance remains unclear.

In an experimental granulomatous colitis mouse model, the systemic administration of anti-TGF- $\beta$ or IL-12 abrogated oral tolerance, ${ }^{35}$ indicating that TGF- $\beta$ and IL-12 have opposite effects in the regulation of the mouse mucosal immune response.

IL-4 knockout mice developed abnormal PPs that lack germinal centres but had intact MLNs. These mice also had defective gut antibody and $\mathrm{T}$ cell responses after immunization with ovalbumin and keyhole limpet hemocyanin, but a normal systemic response to intravenous immunization. ${ }^{36}$
Although IL-4 and IL-10 have been associated with oral tolerance, IL- 4 or IL-10 knockout mice had normal oral tolerance. In an autoimmune uveitis mouse model, IL- 4 or IL-10 knockout mice had defective oral tolerance development in response to oral antigens at doses that induce cytokine production in naïve mice. Reconstitution of IL-10 in IL-10-depleted mice restored the ability to develop oral tolerance; however, reconstitution with IL-4 did not. In an EAE model, IL-10 knockout reduced oral tolerance development, but to a lesser degree than normal mice, while IL-10 knockout mice seemed to develop more severe disease. ${ }^{37}$

Despite many studies showing that IFN- $\gamma$ levels are reduced concomitantly with a decrease in $\mathrm{T}$ cell proliferation in vitro and with the severity of IFN- $\gamma$-mediated autoimmunity, feeding of an antigen at either a high dose $\mathrm{e}^{38}$ or low dose $\mathrm{e}^{39}$ increased IFN- $\gamma$ levels in PPs, MLNs and the spleen ex vivo or after culture with antigen. In IFN- $\gamma$ receptor knockout mice and IL-12 deficient mice, oral tolerance resulted in a normal decrease in delayed-type hypersensitivity (DTH) and antibody response. IFN- $\gamma$ or IFN- $\gamma$ receptor knockout mice still had a decreased Th2 response, indicating that oral tolerance in these mice was not the result of the deviation to Th2 cytokines.

Although the outcomes of blocking IFN- $\gamma$ were controversial, IFN- $\gamma$ was shown to decrease the number of antigen -specific $\mathrm{T}$ cells at effector sites during oral tolerance, and induces effector cell death after stimulation without co-stimulatory cells in vitro. IFN- $\gamma$ knockout mice had a greater T cell response (increased DTH and proliferation) and altered cytokine production compared with normal mice, ${ }^{40}$ suggesting that IFN- $\gamma$ may play a role in the regulation of $\mathrm{T}$ cell responses.

\section{The role of PPs and MLNs in oral tolerance}

The intestinal immune tissue is a primary site of sensitization to oral antigens. Gut-associated lymphoid tissue (GALT) plays an important role in oral tolerance induction. GALT, which is composed of PPs and MLNs, is organised in the intestinal lymphoid follicles. This section describes the involvement of PPs and MLNs in oral tolerance induction. ${ }^{41}$

MLNs are clearly essential for oral tolerance induction; however, the necessity of PPs remains controversial. Fujihashi et al. demonstrated that mice with normal MLNs, but lacking PPs, failed to develop oral tolerance after administration of high-dose ovalbumin, ${ }^{42}$ which was demonstrated by DTH development, induction of an antibody response and $\mathrm{T}$ cell proliferation. However, oral tolerance was induced in response to hapten but not a hapten-ovalbumin conjugate. Conversely, other studies reported that normal oral tolerance can be induced in the absence of PPs. For instance, Spahn et al. found that mice deficient of PPs could develop oral tolerance to ovalbumin, resulting in decreased DTH and IFN- $\gamma$ production and higher TGF- $\beta$ secretion, similar to normal mice, ${ }^{43}$ while oral tolerance induction failed in mice lacking both PPs and MLNs. Worbs et al. verified that MLN lymphadenectomized mice and $\mathrm{C}-\mathrm{C}$ chemokine receptor 7 [a homing receptor for $\mathrm{T}$ cells and dendritic cells (DCs) to LNs] knockout mice failed to develop oral tolerance. ${ }^{44}$

Cellular components of GALT have been shown to be crucial for oral tolerance induction. The role of microfold (M) cells in oral tolerance induction was investigated by Suzuki et al., 
who demonstrated that a delivery system targeting antigens against $M$ cell proteins facilitated oral tolerance induction due to a reduction in Ag-specific CD4+T cells and increased levels of TGF- $\beta 1$ - and IL-10-producing CD25+/CD4+ Tregs in both systemic and mucosal lymphoid tissues. ${ }^{45}$ Moreover, much evidence indicates that B cells are also important for oral tolerance induction. B cell-deficient mice having defective PP and $\mathrm{M}$ cell development fed antigens have defective production of the regulatory cytokines IL-10 and TGF- $\beta$. The EAE mice retained a state of anergy after being fed antigens with more severe encephalomyelitis than normal mice. Other studies have demonstrated that $\mathrm{B}$ cell-deficient mice have the same responses as normal mice to oral ovalbumin administration, which decreased the extent of T cell proliferation and IFN- $\gamma$ secretion, while retaining a decreased DTH response and increased secretion of IL-4, IL-10 and TGF- $\beta$ in vitro. ${ }^{46}$ Furthermore, DCs also play an important role in determining the induction of immunity or tolerance. Gastrointestinal DCs reside in the lamina propria, PPs and MLNs and migrate to the intestinal lymph ducts and thoracic ducts. Viney et al. showed that mice fed the haematopoietic growth factor FMS-like tyrosine kinase-3 (FLT3) ligand, which increases the number of mature DCs in peripheral tissues, had an increased number of DCs in the spleen and mucosal sites. Mice treated with the FLT3 ligand developed greater tolerance to orally administered ovalbumin than control mice, ${ }^{47}$ suggesting that DCs also have an important function in oral tolerance development.

Gastrointestinal DCs are divided into subtypes according to the expression of specific surface molecules and have different locations, as well as T cell stimulatory, cytokine production and migratory activities. It is evident that intestinal and hepatic lymphoid DCs have at least three subsets based on a high or low expression of signal regulatory protein- $\alpha$ (SIRP- $\alpha),{ }^{48}$ and the presence or absence of CD103, CD11b, and CX3CR1. ${ }^{49,50}$ Low SIRP- $\alpha$-expressing DCs are found in the T cell areas of PPs and MLNs, while high SIRP-a-expressing DCs are found outside of these areas. Intravenous lipopolysaccharide administration induced the migration of high SIRP- $\alpha$-expressing DCs to the $\mathrm{T}$ cell areas and enhanced lamina propria DC migration to the draining LNs of the intestines.

In pigs, DCs in the lamina propria are mainly CD11b+/ SIRP- $a+$, while those in the subepithelial dome of PPs are mainly CD11b-/SIRP- $\alpha+$ and those in the interfollicular region of PPs are CD11b-/SIRP- $\alpha-$. In MLNs, the DCs are mainly CD11b+/SIRP- $a-$, while those in the intestinal LNs (after removal of MLNs) are CD11b+ and SIRP- $a$ positive or negative. ${ }^{51}$ These findings indicate that DCs that migrate to the MLNs are mainly from the lamina propria and those in the intestinal LNs have mature phenotypes but are poor $\mathrm{T}$ cell stimulators.

In mice, CD8a+ plasmacytoid DCs in the spleen and MLNs secrete IFN- $\alpha$ after stimulation, ${ }^{52}$ but are less effective at inducing $\mathrm{T}$ cell proliferation and produce more IL-10 and less IFN- $\gamma$ during culture with ovalbumin specific $\mathrm{T}$ cells, as compared with CD8a+ non- plasmacytoid DCs. MLN CD8a+ plasmacytoid DCs drive naïve CD25- T cells into a regulatory phenotype that can suppress proliferation of other $\mathrm{T}$ cells and produce greater amounts of IL- 10 and IL- 4 with some IFN- $\gamma$.

In mice PPs, there are three distinct populations of CD11c+DCs: CD11b-/CD8a+, CD11b+/CD8a- and CD11b-/
CD8 $a-$, respectively. CD8a+DCs are derived from lymphoid precursors and found predominantly in the interfollicular $\mathrm{T}$ cell areas, whereas CD11b+DCs are derived from myeloid precursors and found predominantly in the subepithelial dome. CD11b-/CD8a- DCs are found in the subepithelial dome, ${ }^{52}$ interfollicular $\mathrm{T}$ cell areas, and intraepithelium. ${ }^{53}$ After stimulation with an antigen, CD11b+ cells mature and move to interfollicular $\mathrm{T}$ cell areas to present the acquired antigens to $\mathrm{T}$ cells. An in vitro study showed that $\mathrm{CD} 11 \mathrm{~b}+$ cells from PPs produced higher levels of IL-10 after stimulation with a CD40 ligand trimer and that these DCs stimulated naive $\mathrm{T}$ cells into Th2 cells, whereas PP CD11b+ DCs in the MLNs and peripheral LNs did not secrete IL-10. CD8a+ DCs and CD11b-/ CD8 $a$ - DCs produce IL-12 after stimulation. ${ }^{54}$ In a mouse model of collagen-induced arthritis, mice with oral tolerance had increased numbers CD11b+ DCs and CD25+/CD4+ Tregs in the PPs. The CD11b+DCs produced more IL-10, induced a higher number of CD25+/CD4+ Tregs in vitro and also induced $\mathrm{T}$ cells to produce more IL-10 and TGF- $\beta .^{55}$

The local microenvironment is important for the function of DC subsets. The tolerogenic features of DCs can be influenced by various factors produced by intestinal epithelial cells, such as TGF- $\beta$ and retinoic acid. ${ }^{56,57}$ Another factor is mucin secretion of goblet cells can increase the uptake by CD103+ DCs, which favour the induction of Tregs and promote the development of tolerance response..$^{58}$ In addition, intestinal commensal microbes also play critical roles in shaping the function of DCs and promoting tolerance. For example, DCs cultured in the presence of intestinal epithelial cells and Gram-positive commensal bacteria differentiate into IL-10-producing tolerogenic DCs. ${ }^{59}$ Taken together, these findings establish a key role of the local microenvironment in tolerance regulation of DCs.

\section{The role of commensal flora in oral tolerance}

The intestinal tract is colonized after birth with a variety of ingested environmental and maternal commensal microflora. Previously, it was believed that epithelial cells and microflora do not interact because the microflora would not be able to access pattern recognition receptors on the epithelial cells that recognize common microbial molecules. However, it has been reported that the presence of microflora and their metabolites in the gut is important for the development and maintenance of intestinal immune homeostasis. ${ }^{60}$ For example, commensal bacteria and their metabolites, such as short-chain fatty acids (SCFAs), including acetate, butyrate and propionate, play a role in homeostasis. ${ }^{61,62}$ SCFAs derived from microbiota-mediated digestion of diet fibres prevent inflammation. Recently, it was found that the exposure of monocyte-derived DCs to SCFAs inhibited the release of proinflammatory cytokine induced by incubation with lipopolysaccharides, ${ }^{63}$ which might be due to the effect of lipid mediators that activate anti-inflammatory peroxisome proliferator-activated receptors. ${ }^{64}$

In addition, normal microbial colonization of the intestine is important for the development of tolerance to foods and plays vital roles in the regulation and maintenance of the intestinal barrier. Murine models have been used to demonstrate that bacteria and their components can affect the induction of oral tolerance. For instance, Rodriguez et al. reported that germ-free mice colonized with microbiota from a healthy human infant 
and sensitized with whey protein exhibited milder allergic symptoms following challenge with $\beta$-lactoglobulin than their germ-free counterparts. ${ }^{65}$ In another study, Gaboriau-Routhiau and Moreau demonstrated that feeding mice cholera toxin or labile toxin with ovalbumin prevented the development of oral tolerance; however, as compared with germ-free mice, the presence of gut microflora shortened this effect and facilitated recovery of oral tolerance. ${ }^{66}$

Moreover, Lotz et al. reported that recognition of microbes by TLRs induced tolerance immediately after birth by exposure to exogenous endotoxins to facilitate microbial colonization and the development of intestinal host-microbe homeostasis. ${ }^{67}$ TLR2 has been identified as a regulator of oral tolerance in the gastrointestinal tract. It was recently demonstrated that the probiotic Bifidobacterium breve develops regulatory IL-10 secreting T cells via TLR2 stimulation by CD103+ DCs, thus reducing inflammation in the large intestine ${ }^{68}$ Indeed, it is evident that microbiota have the ability to induce the development of Foxp3+Tregs. In a mouse model, protection against allergic sensitization to food conferred by Clostridia-containing microbiota was associated with an increase in the content of Foxp3+ Tregs in the colonic laminar propria and an increase in the concentration of IgA in faeces. Furthermore, Clostridium spp. ${ }^{69}$ as well as Bacteroides fragilis ${ }^{70}$ is potent inducers of Foxp3+Treg differentiation. Another study revealed that bacterial capsular polysaccharide A can alter the migratory capacity of CD39+/Foxp3+/CD4+ Tregs. ${ }^{71}$ Polysaccharide A-treated mice had increased numbers of CD39+/Foxp3+/CD4+ Tregs homing to the inflamed central nervous system in EAE, which delayed the onset and reduced the severity of EAE, suggesting that bacteria-specific Foxp3+Tregs may also direct anti-inflammatory responses in the gut. Recent studies showed that microbiota can regulate host intestinal immunity by triggering intestinal macrophages to secrete IL- $1 \beta .^{72,73}$ This IL- $1 \beta$ supported GMCSF and IL-22 release by local type 3 innate lymphoid cells (ILC3s). ILC3-derived Il-22 has important function in mucosal defence by strengthening the epithelial barrier. ${ }^{73}$ Meanwhile,
ILC3-derived GM-CSF functions in DC and macrophage secretion of retinoic acid and IL-10, which were found to maintain the homeostasis of mucosal Tregs..$^{72}$ In this process, Tregs plays a major role in promoting B cell class switching to produce IgA response, inducing $\mathrm{T}$ cell anergy of effector cells, and inhibiting the inflammatory process. Together, these data support a role of microbiota in establishment of oral tolerance. It is possible that intestinal microbiota may be important for the development of T-cell tolerance. We proposed a mechanism in which an intestinal microbiota and their products induce oral tolerance by interacting with the intestinal epithelial and immune cells in the mucosal system (Figure 2).

\section{The role of diet in oral tolerance}

Some nutrients, such as retinoic acid (vitamin A) and tryptophan, are known to affect the immune system by conditioning mucosal DCs, thus providing the anti-inflammatory microenvironment needed in the mucosa. ${ }^{74,75}$ Vitamin A upregulates DC enzymes, such as retinal dehydrogenase 2 (RALDH2), which catalyse the synthesis of biologically active retinoic acid to maintain mucosal immunity by generating the homing regulator $\mathrm{T}$ and $\mathrm{B}$ cells. Besides, vitamin $\mathrm{A}$ from diet is essential for the generation of Tregs. ${ }^{76}$ In vitamin A-deficient mice, it was clearly shown the loss of IgA secreting B cells and $\mathrm{T}$ cells in the intestine. ${ }^{77}$ This indicates the role of vitamin $\mathrm{A}$ in inducing oral tolerance.

Vitamin $\mathrm{D}$ has been proposed to play a part in oral tolerance as it can affect $\mathrm{B}$ and $\mathrm{T}$ cell migration, and Th17 cell maturation. ${ }^{78}$ Moreover, vitamin $\mathrm{D}$ is required for the development of subset of intraepithelial CD8aa-expressing T-lymphocytes from the intestinal mucosa. Nevertheless, there was evident showing the involvement of vitamin D-deficiency with increased risk of shrimp and peanut allergy. ${ }^{79}$ While one study found a feasible chance of food allergy after obtained vitamin D supplementation. ${ }^{80}$ However, future investigation of clinical correlation is needed to support the effect of vitamin D on development of oral tolerance.

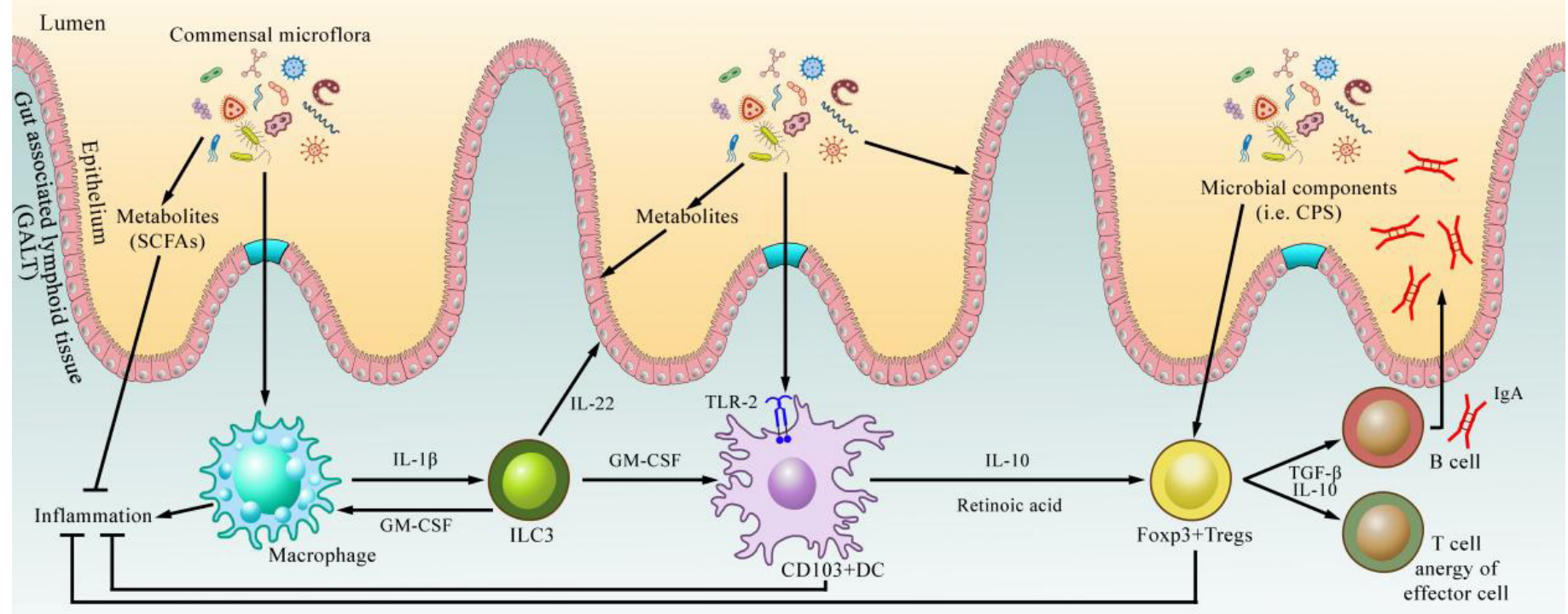

Figure 2. Mechanisms of commensal flora in oral tolerance are multifactorial process involving with the maintenance of the intestinal barrier and interaction with immune cells to support induction of oral tolerance. 


\begin{tabular}{|c|c|c|c|c|c|c|}
\hline 莺产 & 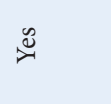 & $\overleftrightarrow{\mathrm{z}}$ & $\cong$ & $\approx$ & $\cong$ & 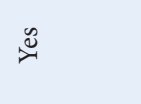 \\
\hline : & 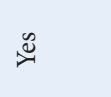 & $\overleftrightarrow{z}$ & $\overleftrightarrow{z}$ & 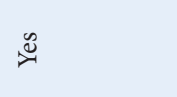 & $\overleftrightarrow{z}$ & $\overleftrightarrow{z}$ \\
\hline 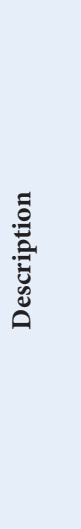 & 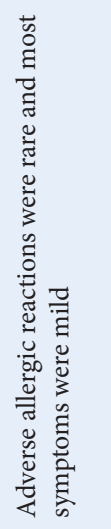 & 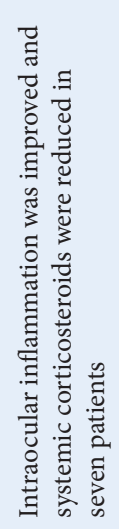 & 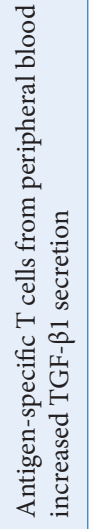 & 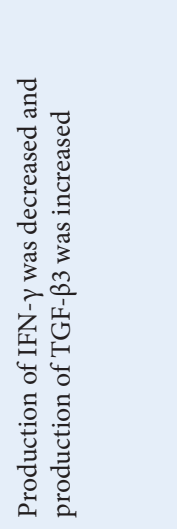 & 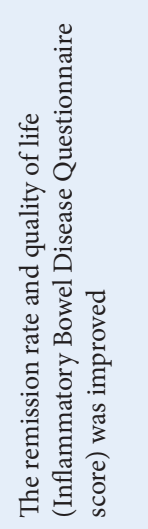 & 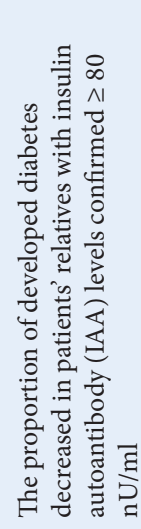 \\
\hline 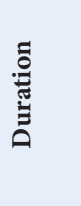 & 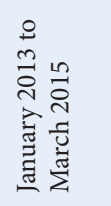 & $\overleftrightarrow{z}$ & $\overleftrightarrow{\mathrm{z}}$ & 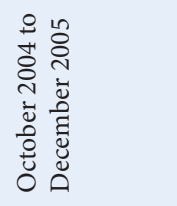 & $\overleftrightarrow{z}$ & 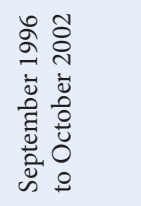 \\
\hline 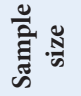 & $\simeq$ & in & m & 腩 & $\vec{m}$ & 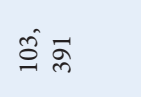 \\
\hline 桇 & $\begin{array}{l}5 \\
15 \\
1 \\
\wedge\end{array}$ & $\overleftrightarrow{z}$ & 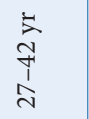 & $\begin{array}{l}5 \\
5 \\
0 \\
1 \\
0 \\
0\end{array}$ & $\begin{array}{l}5 \\
0 \\
\stackrel{0}{\Lambda} \\
\wedge\end{array}$ & $\begin{array}{l}5 \\
5 \\
5 \\
5 \\
0\end{array}$ \\
\hline 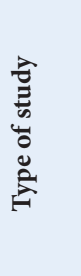 & 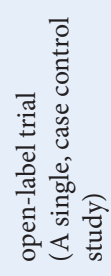 & 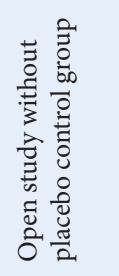 & 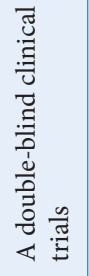 & 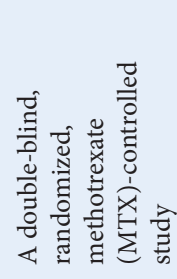 & 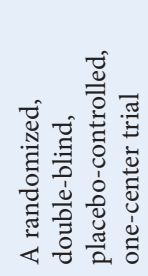 & 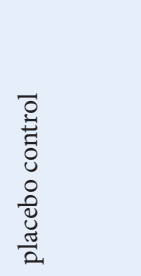 \\
\hline 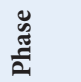 & $\overleftrightarrow{\breve{z}}$ & 点蒙 & $\exists$ & $\exists$ & $\exists$ & 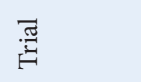 \\
\hline 昱 & 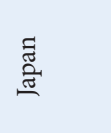 & $\begin{array}{l}\text { 咭 } \\
\text { हूँ }\end{array}$ & $\tilde{s}$ & 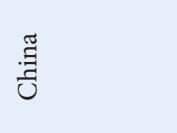 & $s$ & 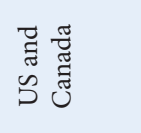 \\
\hline 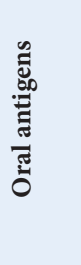 & 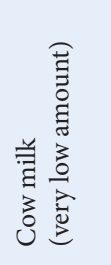 & 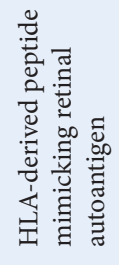 & 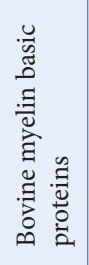 & 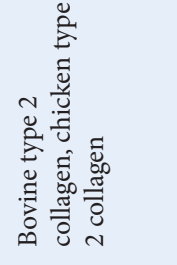 & 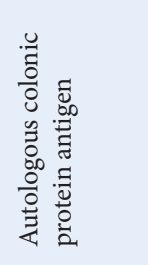 & $\begin{array}{l}\text { 韋 } \\
\text { 参 }\end{array}$ \\
\hline 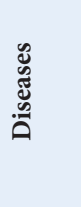 & 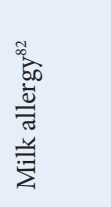 & 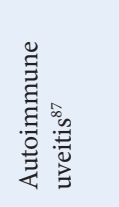 & 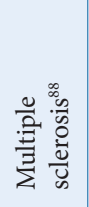 & 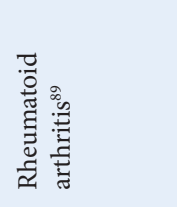 & 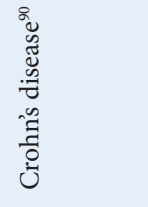 & 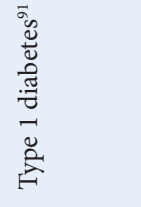 \\
\hline
\end{tabular}

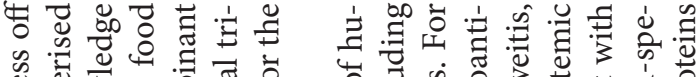

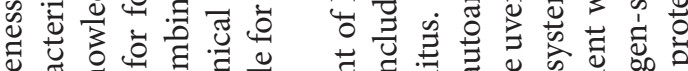

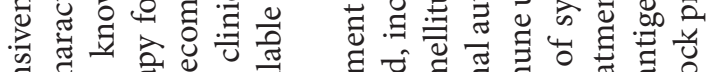

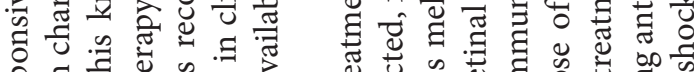

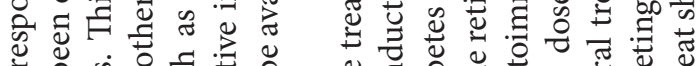

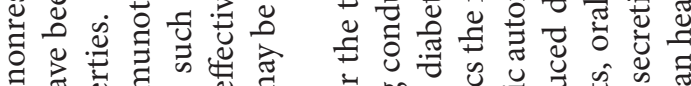

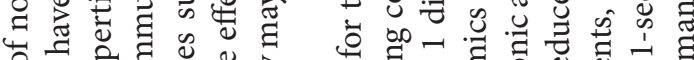

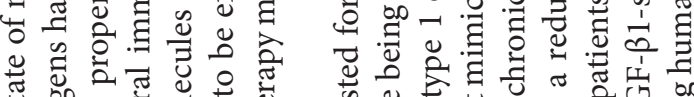

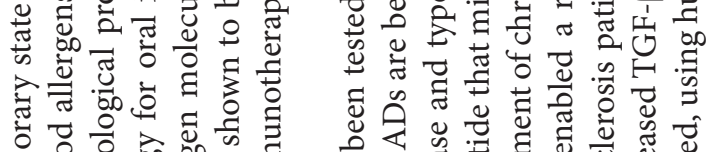

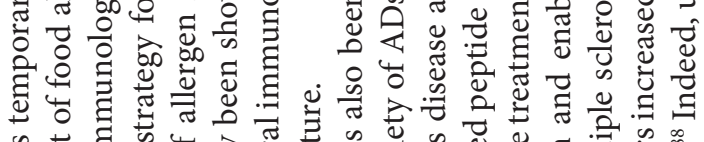

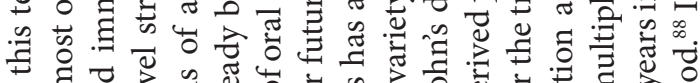
च च्ञ फै 0ี

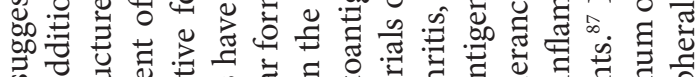
क्ष 过 $\Xi$ के ป 今ं

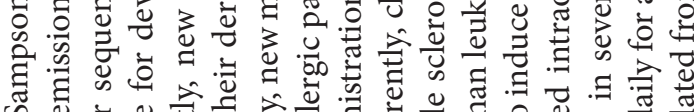

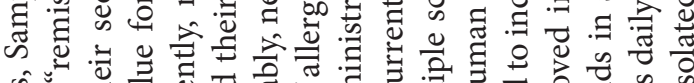

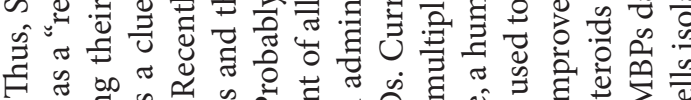

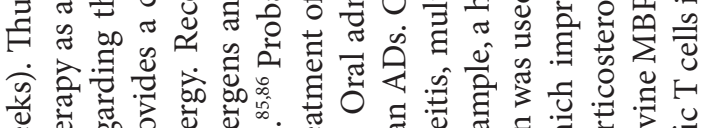

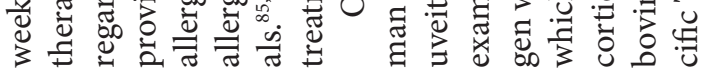

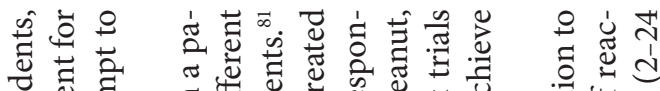

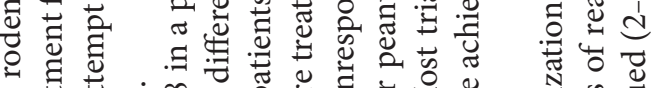

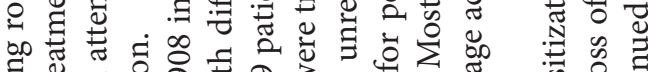

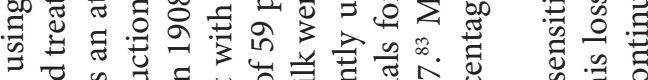

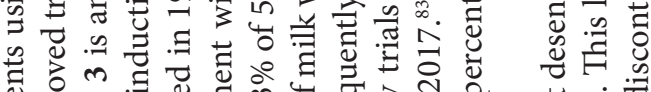

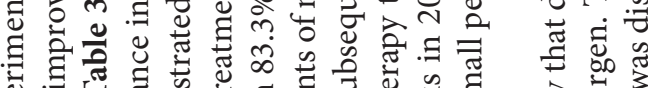
एँ

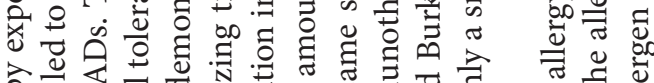

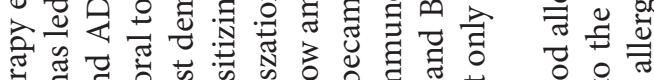

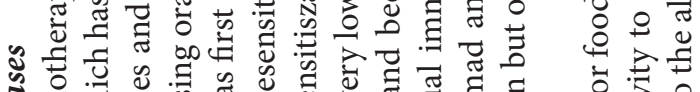

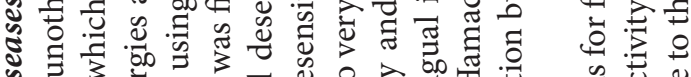

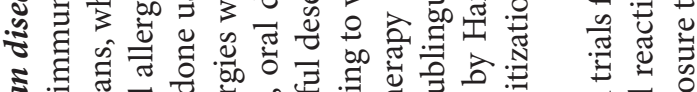

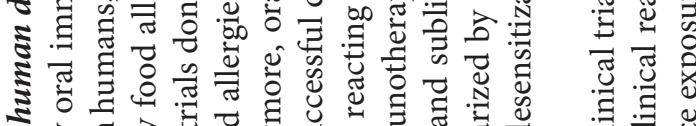

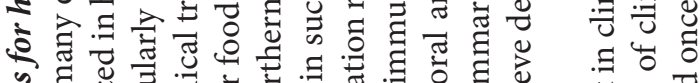

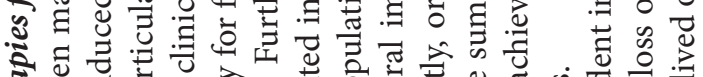

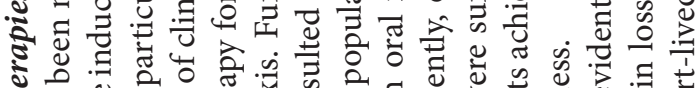

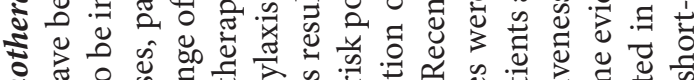

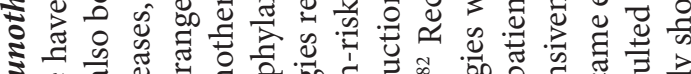
₹

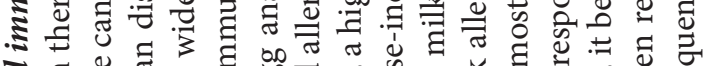

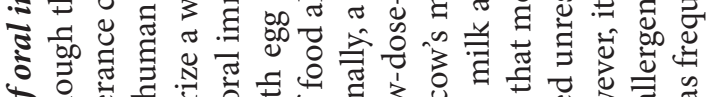

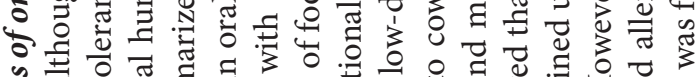

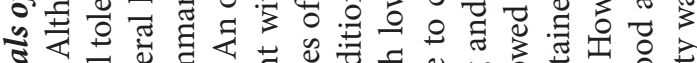

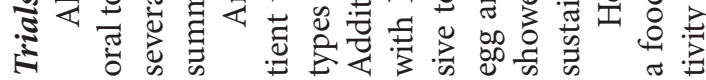


linked to cholera toxin B to develop oral tolerance in patients with Bechet's disease and uveitis enabled the withdrawal of immunosuppressive drugs with no relapse in five of eight patients, and three were relapse-free for 10 months without treatment. In addition, oral administration of bovine type 2 collagen for 3 months resulted in a clinical improvement in eight of 11 juvenile arthritis patients. Six of these patients had decreased IFN- $\gamma$ and increased TGF- $\beta 3$ production by peripheral blood mononuclear cells. Likewise, chicken type 2 collagen has been effective in the treatment of rheumatoid arthritis and is safe for human consumption. ${ }^{89}$ Moreover, in a clinical trial, patients with Crohn's disease given autologous colonic protein antigen by oral administration had a higher remission rate, as compared to the untreated group, although the difference was not statistically significant. ${ }^{90}$ Oral insulin treatment was used to prevent the development of type 1 diabetes mellitus in the relatives of type 1 diabetes mellitus patients. ${ }^{91}$ The oral insulin-treated group had a lower incidence of diabetes among those who had some degree of autoimmunity (insulin autoantibody $\geq 80 \mathrm{nU} /$ $\mathrm{ml})$, but no benefit was achieved in patients without insulin autoantibodies.

Results from the above studies suggest that patients with $\mathrm{ADs}$ are heterogeneous in their responses to oral tolerance induction with the responding group having immunologic profiles that differ from the unresponsive group. Multiple factors are likely involved in individuals with ADs who are more refractory to developing immune tolerance. The observed heterogeneity of responses may be caused by different stages of disease, drug treatments, genetic factors and/or environmental factors among patients.

\section{Conclusions and future perspectives}

Oral tolerance is a type of immune hyporesponsiveness to gastrointestinal antigens that can be acquired through oral administration. This review discusses a number of mechanisms of immunological hyporesponsiveness and highlights possible methods to facilitate the prevention or therapy of ADs and allergy. Although the mechanisms underlying oral tolerance are complex and involve multiple cellular and molecular processes, we have reviewed four mechanisms of immunological hyporesponsiveness including (1) anergy or the suppression of specific T cell subsets and Th1 and/or Th2 cytokines, (2) suppression by Th2 or regulatory cytokines, (3) bystander suppression by Tregs, (4) and induction of antibody response. Although most T cell subsets (Th1, Th2 and Tregs) and their cytokines are clearly involved in the development of oral tolerance, little is known about the underlying signaling pathways that regulate the immune responses responsible for oral tolerance. A better understanding of these processes is needed in order to identify new targets for modulating tolerance.

There is much evidence that PPs, MLNs and DCs actively participate in maintaining intestinal immune homeostasis and play important roles during oral tolerance induction. Likewise, there is increasing interest in the possible role of dietary factors in maintenance of mucosal immunity and development of oral tolerance. Interestingly, microflora in the gut also contributes to oral tolerance induction by interacting with intestinal epithelial cells and delivering tolerogenic signals that are transmitted to the immune system. Microflora and their metabolites, such as SCFAs, including acetate, butyrate and propionate, also play a role in homeostasis and immune system development in the gut. When these factors are disrupted, the system may be biased towards the Th2 phenotype and interfere with Treg development. There is a considerable interest in investigating the role of the intestinal microflora and metabolites in oral tolerance induction. Perhaps, probiotics may be useful materials for oral tolerance induction.

At present, clinical trials of oral tolerance are being conducted in a variety of human diseases, including allergy and ADs. However, the success of oral administration to induce hyporesponsiveness to gastrointestinal antigens in humans is limited, which might be due to the fact that most studies of oral tolerance induction have been conducted in non-human subjects, such as rodents and larger mammals (i.e. rabbits, pigs, sheep and non-human primates). It is possible that these animals may not respond to oral immunity similarly to humans. Moreover, in regard to the physiology of human intestinal absorption, a sufficient dose for humans may differ from those needed for other animals. Furthermore, there are individual genetic differences and genetic disorders in humans that have not yet been identified, which may explain why trials of oral tolerance in patients are more difficult than in animal models and why there is heterogeneity in the response to oral antigens. Indeed, additional studies on the variations and formulations of antigens to induce oral tolerance are required to determine the most effective method for humans. Lastly, we need to pay more attention to the short- and long-term safety of oral tolerance. In summary, while there is still a long way to go in better understanding of oral tolerance induction, the continued progress in this field has brought us closer to effective clinical development of oral tolerance for the treatment of human diseases.

\section{Acknowledgements}

We thank Dr James Kelley, World Health Organization, Western Pacific Regional office, Manila, Philippines, for proofreading the manuscript.

\section{Conflicts of interest}

All contributing authors declare no conflicts of interest.

\section{References}

1. Kierszenbaum AL, Tres LL. Histology and Cell Biology: An Introduction to Pathology. 4th ed. Philadelphia: Elsevier Health Sciences; 2015.

2. Pabst O, Mowat A. Oral tolerance to food protein. Mucosal Immunol. 2012; 5:232-39.

3. Issa F, Wood KJ. Translating tolerogenic therapies to the clinic - where do we stand? Front Immunol. 2012;3:1-14.

4. Microbiology and Immunology Mobile [internet].2016 [cited 2016 Aug 10] Available from: http://www.microbiologybook.org/mobile/m.immuno-16. htm

5. Tordesillas L, Berin MC. Mechanisms of Oral Tolerance. Clin Rev Allerg Immunol. 2018. doi:10.1007/s12016-018-8680-5.

6. Smolkin Y, Grishchenko E. What is known about Oral tolerance? Int J Aller Medication. 2016;2:1-8.

7. Kurian SM, Whisenant TC, Mathew JM, Miller J, Leventhal JR Transcriptomic studies in tolerance: Lessons learned and the path forward. Hum Immunol. 2018;79:395-401. 
8. Mayer L, Shao L. Therapeutic potential of oral tolerance. Nat Rev Immunol. 2004;4:407-19.

9. Raphael I, Nalawade S, Eagar TN, Forsthuber TG. T cell subsets and their signature cytokines in autoimmune and inflammatory diseases. Cytokine. 2015;74:5-17.

10. George A, Hultkrantz S, Raghavan S, Czerkinsky C, Lebens M, Telemo E, et al. Oral tolerance induction by mucosal administration of cholera toxin $\mathrm{B}$-coupled antigen involves $\mathrm{T}$-cell proliferation in vivo and is not affected by depletion of CD25+ T cells. Immunology. 2006;118:311-20. 11.

Chen Y, Inobe J, Kuchroo VK, Baron JL, Janeway CA Jr , Weiner HL. Oral tolerance in myelin basic protein T-cell receptor transgenic mice: suppression of autoimmune encephalomyelitis and dose-dependent induction of regulatory cells. Proc Natl Acad Sci U S A, 1996;93:388-91.

12. Inada S, Yoshino S, Haque M, Ogata Y, Kohashi O. Clonal anergy is a potent mechanism of oral tolerance in the suppression of acute antigen-induced arthritis in rats by oral administration of the inducing antigen. Cell Immunol. 1997; 175:67-75.

13. Weiner $\mathrm{H}$, Cunha $\mathrm{A}$, Quintana $\mathrm{F}, \mathrm{Wu} \mathrm{H}$. Oral tolerance. Immunol Rev. 2011;241:241-59.

14. Millington $\mathrm{O}$, Mowat A, Garside P. Induction of bystander suppression by feeding antigen occurs despite normal clonal expansion of the bystander $\mathrm{T}$ cell population. J Immunol. 2004;173:6059-64

15. Karlsson M, Kahu H, Hanson L, Telemo E, Dahlgren U. Tolerance and bystander suppression, with involvement of CD25-positive cells, is induced in rats receiving serum from ovalbumin-fed donors. Immunology. 2000; 100:326-33.

16. Curotto de Lafaille MA, Kutchukhidze N, Shen S, Ding Y, Yee H, Lafaille J. Adaptive Foxp3+ regulatory T cell-dependent and -independent control of allergic inflammation. Immunity. 2008;29:114-26.

17. Smaldini P, Orsini Delgado M, Fossati C, Docena G. Orally-induced intestinal CD4+ CD25+ FoxP3+ Treg controlled undesired responses towards oral antigens and effectively dampened food allergic reactions. PLoS One. 2015;10:e0141116.

18. Hadis U, Wahl B, Schulz O, Hardtke-Wolenski M, Schippers A, Wagner N, et al. Intestinal tolerance requires gut homing and expansion of FoxP3+ regulatory T cells in the lamina propria. Immunity. 2011;34:237-46.

19. Mucida D, Kutchukhidze N, Erazo A, Russo M, Lafaille J, Curotto de Lafaille MA. Oral tolerance in the absence of naturally occurring Tregs. J Clin Invest. 2005; 115:1923-33.

20. Kapp K, Maul J, Hostmann A, Mundt P, Preiss J, Wenzel A, et al. Modulation of systemic antigen-specific immune responses by oral antigen in humans. Eur J Immunol. 2010;40:3128-37.

21. Long S, Rieck M, Tatum M, Bollyky P, Wu R, Muller I, et al. Low-dose antigen promotes induction of FOXP3 in human CD4+ T cell. J Immunol. 2011;187:3511-20.

22. Zivny JH, Moldoveanu Z, Vu HL, Russell MW, Mestecky J, Elson CO. Mechanisms of immune tolerance to food antigens in humans. Clin Immunol. 2001;101:158-68.

23. Kagnoff F. Effects of antigen-feeding on intestinal and systemic immune responses. III. Antigen-specific serum-mediated suppression of humoral antibody responses after antigen feeding. Cell Immunol. 1978;40:186-203.

24. Chalon P, Milne W, Vaerman P. In vitro immunosuppressive effect of serum from orally immunized mice. Eur J Immunol. 1979;9:747-51.

25. Burton T, Tamayo M, Stranks J, Koleoglou J, Oettgen C.Allergen-specific IgG antibody signaling through $\mathrm{Fc} \gamma \mathrm{RIIb}$ promotes food tolerance. J Allergy Clin Immunol. 2018;141:189-201.

26. Du Toit G, Roberts G, Sayre H, Bahnson T, Radulovic S, Santos F, et al. Randomized trial of peanut consumption in infants at risk for peanut allergy. N Engl J Med. 2015;372:803-13.

27. Perezabad L, Reche M, Valbuena T, López-Fandiño R, Molina E, López -Expósito I. Oral food desensitization in children with IgE-mediated cow's milk allergy: immunological changes underlying desensitization. Allergy Asthma Immunol Res. 2017;9:35-42.

28. Castro-Junior A, Horta B, Gomes-Santos A, Cunha A, Silva Steinberg $\mathrm{R}$, Nascimento D, et al. Oral tolerance correlates with high levels of lymphocyte activity. Cell Immunol. 2012;280:171-81.

29. Miron N, Feldrihan V, Berindan-Neagoe I, Cristea V. The role of Staphylococcal enterotoxin A in achieving oral tolerance to myelin basic protein in adult mice. Immunol Invest. 2014;43:267-77.

30. Rekima A, Macchiaverni P, Turfkruyer M, Holvoet S, Dupuis L, Baiz $\mathrm{N}$, et al. Long-term reduction in food allergy susceptibility in mice by combining breastfeeding-induced tolerance and TGF-beta-enriched formula after weaning. Clin Exp Allergy. 2017;47:565-76.
31. Friedman A. and Weiner HL. Induction of anergy or active suppression following oral tolerance is determined by antigen dosage. Proc Natl Acad Sci USA. 1994;91:6688-92.

32. Skapenko A, Kalden JR, Lipsky PE, Schulze-Koops H. The IL-4 receptor alpha-chain-binding cytokines, IL-4 and IL-13, induce forkhead box P3 -expressing CD25+CD4+ regulatory T cells from CD25-CD4+ precursors. J Immunol. 2005;175:6107-16.

33. Mueller T, Terada T, Rosenberg IM, Shibolet O, Podolsky DK. Th2 cytokines down-regulate TLR expression and function in human intestinal epithelial cells. J Immunol. 2006;176:5805-14.

34. Tunis MC, Dawod B, Carson KR, Veinotte LL, Marshall JS. Toll-like receptor 2 activators modulate oral tolerance in mice. Clin Exp Allergy. 2015;45:1690-702

35. Neurath MF, Fuss I, Kelsall BL, Presky DH, Waegell W, Strober W. Experimental granulomatous colitis in mice is abrogated by induction of TGF-beta-mediated oral tolerance. J Exp Med. 1996;183:2605-16.

36. Barone KS, Tolarova DD, Ormsby I, Doetschman T, Michael JG. Induction of oral tolerance in TGF-beta 1 null mice. J Immunol, 1998.161:154-60.

37. Gonnella PA, Waldner HP, Kodali D, Weiner HL. Induction of low dose oral tolerance in IL-10 deficient mice with experimental autoimmune encephalomyelitis. J Autoimmun. 2004;23:193-200.

38. Parameswaran N, Samuvel J, Kumar R, Thatai S, Bal V, Rath S, et al. Oral tolerance in $\mathrm{T}$ cells is accompanied by induction of effector function in lymphoid organs after systemic immunization. Infect Immun. 2004;72 3803-11.

39. Kolker O, Klein A, Alper R, Menachem Y, Shibolet O, Rabbani E, et al. Early expression of interferon gamma following oral antigen administration is associated with peripheral tolerance induction. Microbes Infect. 2003;5: 807-13.

40. Margenthaler JA, Kataoka M, Flye WM. Oral and portal venous tolerance in the interferon-gamma knockout (GKO) mouse. J Surg Res. 2004;119: 107-12.

41. Faria C, Reis S, Mucida D. Tissue adaptation: implications for gut immunity and tolerance. J Exp Med. 2017;214:1211-26.

42. Fujihashi K, Dohi T, Rennert PD, Yamamoto M, Koga T, Kiyono H, et al Peyer's patches are required for oral tolerance to proteins. Proc Natl Acad Sci U S A. 2001;98:3310-5

43. Spahn TW, Weiner HL, Rennert PD, Lugering N, Fontana A, Domschke $\mathrm{W}$, et al. Mesenteric lymph nodes are critical for the induction of high-dose oral tolerance in the absence of Peyer's patches. Eur J Immunol. 2002;32: 1109-13.

44. Worbs T, Bode U, Yan S, Hoffmann MW, Hintzen G, Bernhardt G, et al Oral tolerance originates in the intestinal immune system and relies on antigen carriage by dendritic cells. J Exp Med. 2006;203:519-27.

45. Suzuki H, Sekine S, Kataoka K, Pascual DW, Maddaloni M, Kobayashi R, et al. Ovalbumin-Protein $\sigma 1 \mathrm{M}$ Cell Targeting Facilitates Oral Tolerance with Reduction of Antigen-Specific CD4+ T Cells. Gastroenterology. 2008;135: 917-25.

46. Alpan O, Rudomen G, Matzinger P. The role of dendritic cells, B cells, and $M$ cells in gut-oriented immune responses. J Immunol. 2001;166:4843-52.

47. Viney L, Mowat M, O’Malley M, Williamson E, Fanger A. Expanding dendritic cells in vivo enhances the induction of oral tolerance. J Immunol. 1998;160:5815-25.

48. Turnbull L, Yrlid U, Jenkins D, Macpherson G. Intestinal dendritic cell subsets: differential effects of systemic TLR4 stimulation on migratory fate and activation in vivo. J Immunol. 2005;174:1374-84.

49. Chang Y, Ko J, Kweon N. Mucosal dendritic cells shape mucosal immunity. Exp Mol Med. 2014;46:e84.

50. Persson K, Scott L, Mowat M, Agace W. Dendritic cell subsets in the intestinal lamina propria: ontogeny and function. Eur J Immunol. 2013;43 3098-107.

51. Bimczok D, Sowa N, Faber-Zuschratter H, Pabst R, Rothkotter J. Site -specific expression of CD11b and SIRPalpha (CD172a) on dendritic cells: implications for their migration patterns in the gut immune system. Eur J Immunol. 2005;35:1418-27.

52. Bilsborough J, George TC, Norment A, Viney JL. Mucosal CD8alpha+ DC, with a plasmacytoid phenotype, induce differentiation and support function of $\mathrm{T}$ cells with regulatory properties. Immunology. 2003;108: 481-92.

53. Iwasaki A and Kelsall BL. Localization of distinct Peyer's patch dendritic cell subsets and their recruitment by chemokines macrophage inflammatory protein (MIP)-3alpha, MIP-3beta, and secondary lymphoid organ chemokine. J Exp Med, 2000;191:1381-94. 
54. Iwasaki A and Kelsall BL. Unique functions of CD11b+, CD8 alpha+, and double-negative Peyer's patch dendritic cells. J Immunol. 2001;166: 4884-90.

55. Min SY, Park KS, Cho ML, Kang JW, Cho YG, Hwang SY, et al. Antigen -induced, tolerogenic CD11c+, CD11b+ dendritic cells are abundant in Peyer's patches during the induction of oral tolerance to type II collagen and suppress experimental collagen-induced arthritis. Arthritis Rheum. 2006;54:887-98.

56. Li MO, Flavell RA. TGF-beta: a master of all T cell trades. Cell. 2008;134: 392-404.

57. Manicassamy S, Pulendran B. Retinoic acid-dependent regulation of immune responses by dendritic cells and macrophages. Semin Immunol. 2009;21:22-7.

58. McDole R, Wheeler W, McDonald G, Wang B, Konjufca V, Knoop KA, et al. Goblet cells deliver luminal antigen to CD103+ dendritic cells in the small intestine. 2012.Nature.2012;483:345-49.

59. Zeuthen LH, Fink LN, Frokiaer H. Epithelial cells prime the immune response to an array of gut-derived commensals towards a tolerogenic phenotype through distinct actions of thymic stromal lymphopoietin and transforming growth factor-beta. Immunology. 2008;123:197-208.

60. Murgas Torrazza R, Neu J. The developing intestinal microbiome and its relationship to health and disease in the neonate. J Perinatol. 2011;31:29-34.

61. Nastasi C, Candela M, Bonefeld CM, Geisler C, Hansen M, Krejsgaard T, et al. The effect of short-chain fatty acids on human monocyte-derived dendritic cells. Sci Rep. 2015;5:16148.

62. Singh N, Gurav A, Sivaprakasam S, Brady E, Padia R, Shi H, et al. Activation of Gpr109a, receptor for niacin and the commensal metabolite butyrate, suppresses colonic inflammation and carcinogenesis. Immunity. 2014;40: 128-39.

63. Nastasi C, Candela M, Bonefeld CM, Geisler C, Hansen M, Krejsgaard T, et al. The effect of short-chain fatty acids on human monocyte-derived dendritic cells. Sci Rep. 2015;5:16148.

64. Varga T, Nagy L. Nuclear receptors, transcription factors linking lipid metabolism and immunity: the case of peroxisome proliferator-activated receptor gamma. Eur J Clin Invest. 2008;38:695-707.

65. Rodriguez B, Prioult G, Hacini-Rachinel F, Moine D, Bruttin A, Ngom-Bru $\mathrm{C}$, et al. Infant gut microbiota is protective against cow's milk allergy in mice despite immature ileal T-cell response. FEMS Microbiol Ecol. 2012;79: 192-202.

66. Gaboriau-Routhiau V, Moreau MC. Gut flora allows recovery of oral tolerance to ovalbumin in mice after transient breakdown mediated by cholera toxin or Escherichia coli heat-labile enterotoxin. Pediatr Res. 1996; 39:625-9.

67. Lotz M, Gutle D, Walther S, Menard S, Bogdan C, Hornef MW. Postnatal acquisition of endotoxin tolerance in intestinal epithelial cells. J Exp Med. 2006;203:973-84.

68. Jeon SG, Kayama H, Ueda Y, Takahashi T, Asahara T, Tsuji H, et al. Probiotic Bifidobacterium breve induces IL-10-producing $\operatorname{Tr} 1$ cells in the colon. PLoS Pathog. 2012;8:e1002714.

69. Atarashi K, Tanoue T, Oshima K, Suda W, Nagano Y, Nishikawa H, et al. Treg induction by a rationally selected mixture of Clostridia strains from the human microbiota. Nature. 2013;500:232-6.

70. Round JL, Mazmanian SK. Inducible Foxp3+ regulatory T-cell development by a commensal bacterium of the intestinal microbiota. Proc Natl Acad Sci U S A. 2010;107:12204-9.

71. Wang Y, Begum-Haque S, Telesford KM, Ochoa-Reparaz J, Christy M, Kasper EJ, et al. A commensal bacterial product elicits and modulates migratory capacity of $\mathrm{CD} 39(+) \mathrm{CD} 4 \mathrm{~T}$ regulatory subsets in the suppression of neuroinflammation. Gut Microbes. 2014;5:552-61.

72. Mortha A, Chudnovskiy A, Hashimoto D, Bogunovic M, Spencer SP, Belkaid Y, et al. Microbiota-dependent crosstalk between macrophages and ILC3 promotes intestinal homeostasis. Science. 2014;343:1249288.
73. Stefka AT, Feehley T, Tripathi P, Qiu J, McCoy K, Mazmanian SK, et al Commensal bacteria protect against food allergen sensitization. Proc Natl Acad Sci. 2014;111:13145-50.

74. Yokota A, Takeuchi H, Maeda N, Ohoka Y, Kato C, Song SY, et al. GM -CSF and IL-4 synergistically trigger dendritic cells to acquire retinoic acid -producing capacity. Int Immunol. 2009;21:361-77.

75. Fallarino F, Grohmann U, You S, McGrath BC, Cavener DR, Vacca C, et al. The combined effects of tryptophan starvation and tryptophan catabolites down-regulate $\mathrm{T}$ cell receptor zeta-chain and induce a regulatory phenotype in naive T cells. J Immunol. 2006;176:6752-61.

76. Swantje H, Ahrendt M, Bode U, Wahl B, Kremmer E, Förster R, et al. Stromal mesenteric lymph node cells are essential for the generation of gut-homing T cells in vivo. J Exp Med. 2008;205:2483-90.

77. Iwata M, Hirakiyama A, Eshima Y, Kagechika H, Kato C, Song S. Retinoic acid imprints gut-homing specificity on T cells. Immunity. 2004;21:527-38.

78. Chang J, Cha H, Lee D, Seo K, Kweon M.1, 25-Dihydroxyvitamin D 3 inhibits the differentiation and migration of Th 17 cells to protect against experimental autoimmune encephalomyelitis. PLoS One. 2010;5:p.e12925

79. Sharief S, Jariwala S, Kumar J, Muntner P, Melamed M.Vitamin D levels and food and environmental allergies in the United States: results from the National Health and Nutrition Examination Survey 2005-2006. J Allergy Clin Immunol. 2011;127:1195-202.

80. Milner J, Stein D, McCarter R, Moon R. Early infant multivitamin supplementation is associated with increased risk for food allergy and asthma. Pediatrics. 2004;114:27-32.

81. Patriarca G, Nucera E, Roncallo C, Pollastrini E, Bartolozzi F, De Pasquale T, et al. Oral desensitizing treatment in food allergy: clinical and immunological results. Aliment Pharmacol Ther. 2003;17:459-65.

82. Yanagida N, Sato S, Asaumi T, Okada Y, Ogura K, Ebisawa M. A single -center, case-control study of low-dose-induction oral immunotherapy with cow's milk. Int Arch Allergy Immunol. 2015;168:131-7.

83. Hamad A, Burks W. Oral tolerance and allergy. Semin Immunol. 2017;30: 28-35.

84. Sampson HA, O’Mahony L, Burks AW, Plaut M, Lack G, Akdis CA. Mechanisms of food allergy. J Allergy Clin Immunol. 2018;141:11-9.

85. Valenta R, Campana R, Focke-Tejkl M, NiederbergerVaccine V. Development for allergen-specific immunotherapy based on recombinant allergens and synthetic allergen peptides: Lessons from the past and novel mechanisms of action for the future. J Allergy Clin Immunol. 2016;137: 351-7.

86. Valenta $\mathrm{R}$, Campana R, Niederberger V. Recombinant allergy vaccines based on allergen-derived B cell epitopes. Immunol Lett. 2017;30:67-80.

87. Thurau SR, Diedrichs-Mohring M, Fricke H, Arbogast S, Wildner G. Molecular mimicry as a therapeutic approach for an autoimmune disease: oral treatment of uveitis-patients with an MHC-peptide cross reactive with autoantigen--first results. Immunol Lett. 1997;57:193-201.

88. Fukaura H, Kent SC, Pietrusewicz MJ, Khoury SJ, Weiner HL, Hafler DA. Induction of circulating myelin basic protein and proteolipid protein -specific transforming growth factor-betal-secreting Th3 T cells by oral administration of myelin in multiple sclerosis patients. J Clin Invest. 1996; 98:70-7.

89. Wei W, Zhang LL, Xu JH, Xiao F, Bao CD, Ni LQ, et al. A multicenter, double-blind, randomized, controlled phase III clinical trial of chicken type II collagen in rheumatoid arthritis. Arthritis Res Ther. 2009;11:R180.

90. Margalit M, Israeli E, Shibolet O, Zigmond E, Klein A, Hemed N, et al. A double-blind clinical trial for treatment of Crohn's disease by oral administration of Alequel, a mixture of autologous colon-extracted proteins: a patient-tailored approach. Am J Gastroenterol. 2006;101:561-8.

91. Skyler S, Krischer P, Wolfsdorf J, Cowie C, PalmerP, Greenbaum C, et al. Effects of oral insulin in relatives of patients with type 1 diabetes: The Diabetes Prevention Trial--Type 1. Diabetes Care. 2005;28:1068-76. 